Proceedings

\title{
Environmental Drivers of Plant Diversity of Chalk Grasslands in North-Western France ${ }^{\dagger}$
}

Antoine Tardif ${ }^{*}$, Pauline Boubert ${ }^{1}$, Méghan Boulembert ${ }^{1}$, Loan Madej ${ }^{1}$, Maxime Burst ${ }^{2 *}$, Manuella Catterou ${ }^{1}$, Françoise Dubois ${ }^{1}$, Frédéric Dubois ${ }^{1}$, Jérôme Lacoux ${ }^{1}$, Romain Ulmer ${ }^{1}$, Thierry Dutoit ${ }^{3 *}$, François Mesleard ${ }^{4 *}$, Hugo Fontès $^{4 *}$, Grégory Loucougaray ${ }^{5 *}$, Alice Michelot-Antalik ${ }^{6 *}$, Sylvain Plantureux ${ }^{6 *}$, Didier Alard ${ }^{7 *}$, Servane Lemauviel-Lavenant $^{8 *}$, Sylvain Diquelou ${ }^{8 *}$, Guillaume Meire ${ }^{9}$, Anne Bonis $^{2 *}$ and Olivier Chabrerie ${ }^{1 *}$

${ }^{1}$ EDYSAN (Écologie et Dynamique des Systèmes Anthropisés), UMR CNRS 7058, Université de Picardie Jules

Verne, 33 Rue St Leu, 80039 Amiens Cedex, France

2 GEOLAB UMR CNRS-Université Clermont Auvergne, 4 rue Ledru, 63057, Clermont-Ferrand Cedex 1, France ${ }^{3}$ Institut Méditerranéen de Biodiversité et d'Ecologie Marine et Continentale (IMBE) UMR CNRS 7263, IRD 237, IUT Avignon, Site Agroparc BP 61207, 337 chemin des Meinajaries, 84911 Avignon cedex 09, France ${ }^{4}$ Institut de Recherche de la Tour du Valat, Le Sambuc, 13200 Arles, France.

${ }^{5}$ Univ. Grenoble Alpes, INRAE, LESSEM, 38402 St-Martin-d'Hères, France

${ }^{6}$ UMR Université de Lorraine, ENSAIA, INRAE, 2 avenue de la forêt de Haye, 54500 Vandoeuvre-lès-Nancy ${ }^{7}$ UMR 1202 INRAE - BIOGECO, Allée Geoffroy Saint-Hilaire, Bâtiment B2 - CS 50023, 33615 Pessac Cedex ${ }^{8}$ UMR INRAE Ecophysiologie Végétale Agronomie \& nutrition NCS, UFR des Sciences - département Biologie Sciences de la Terre, Université de Caen Normandie, Esplanade de la Paix, CS 14032, 14032 Caen Cedex, France

${ }^{9}$ Conservatoire des Espaces Naturels Hauts-de-France, France

* Members of SURPAS Consortium https://geolab.uca.fr/geolab/actualites/projet-de-recherche-surpas-155637.kjsp?RH=1542017095519

E-mail: antoine.tardif@usherbrooke.ca

\begin{abstract}
In Europe, chalk grasslands are considered as biodiversity hotspots, hosting rare species (e.g. orchid and endemic species). However, since the mid $20^{\text {th }}$ century, this habitat is threatened by changes in agricultural practices, especially the decline of pastoralism and recent anthropogenic nitrogen inputs. In this national research project ('SURPAS' project, French Ministry for the Ecological Transition, UMS PatriNat, OFB), we aimed to identify the main factors driving plant composition and richness of these chalk grassland communities to update our knowledge and recommendations in terms of conservation measures. The study was carried out in Natura 2000 chalk grassland sites in the valley of Somme river, in north-western France. We performed botanical and habitat surveys (topography and soil measures, vegetation structure, composition and biomass, fodder quality) at two spatial scales, in $1 \times 1 \mathrm{~m}$ and $4 \times 4 \mathrm{~m}$ plots. Data were analyzed using multivariate analyses (CCA) and mixed models. Our main results showed that plant height, South exposure, litter thickness and woody species abundance drive composition and richness species, and that nitrogen inputs in the ecosystem, Brachypodium pinnatum dominance and tree colonization were currently the major threats to the conservation of the diversity of chalk grasslands.
\end{abstract}

Keywords: plant community; sheep grazing; Brachypodium pinnatum; species composition; species richness; soil composition; fodder quality; biomass; ecosystem services; Natura 2000; conservation 